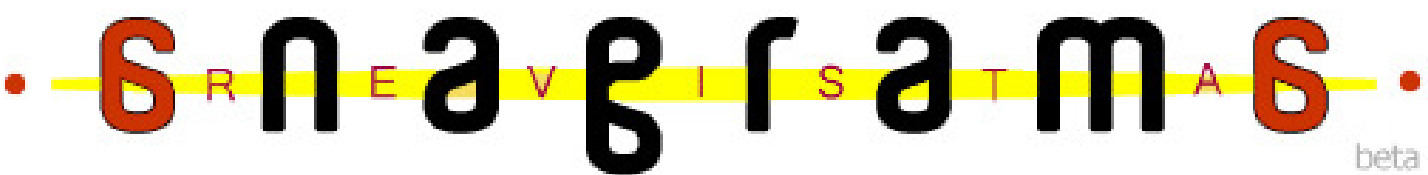

\section{Fora da ordem eleitoral: a cobertura das políticas públicas sociais em "Folha" e "Correio" em 2010}

\section{Juliana Doretto ${ }^{\top}$ \\ Juliana Freitas ${ }^{2}$ \\ Mirele Pinheiro ${ }^{3}$}

\section{Resumo}

Neste artigo, analisamos a cobertura das eleições brasileiras de 2010 em dois jornais diários, "Folha de S. Paulo" e "Correio Braziliense", com o objetivo de verificar se os periódicos cobriram a agenda social, e suas políticas públicas, durante o debate eleitoral. Os dados encontrados nos permitem afirmar que os jornais deixaram de abordar pautas envolvendo políticas públicas, e, quando o fizeram, promoveram uma discussão superficial: faltaram enquadramentos diversificados e poucos temas foram debatidos houve perceptível concentração na temática do aborto.

Palauras-chaue: eleições, políticas públicas, Folha de S.Paulo, Correio Braziliense

\section{Introdução}

Quando e onde surge uma política pública? Ela sai do ar-condicionado dos prédios públicos? Do povo, na rua? Das lideranças das organizações não-governamentais? Segundo Canela, ela nasce na disputa eleitoral. "Neste momento diferentes propostas de intervenção na realidade são apresentadas ao eleitor, que deverá escolher aquela que lhe

\footnotetext{
${ }^{1}$ Jornalista e mestre em ciências da comunicação pela Universidade de São Paulo e doutoranda na mesma área pela Universidade Nova de Lisboa jdoretto@gmail.com

${ }^{2}$ Graduanda do curso de jornalismo da UnB (Universidade de Brasília) jurfreitas@gmail.com

${ }^{3}$ Graduada em artes visuais pela UnB mirelepinheiro@hotmail.com
} 
parecer mais apropriada nesta espécie de mercado de idéias (ou promessas)" (Canela, 2008: 21). Esse demonstrar de propostas não se concretiza, na sociedade civil organizada, sem a ajuda da imprensa: a teoria democrática "aponta para os meios de comunicação o papel de 'mercado de ideias' numa democracia, em que as diversas opiniões da sociedade podem ser ouvidas e discutidas" (Traquina, 2005: 128).

Nesse cenário, ocupamo-nos, dentro da pauta de políticas públicas, daquelas que se voltam para o "social”. Essa pesquisa se faz necessária porque há um vácuo verificado na cobertura jornalística nacional nessa área: de maneira geral, a imprensa peca ao levantar questões sobre as estratégias públicas em temas sociais, seja por discutir pouco o assunto, seja por debatê-lo de forma superficial ou com poucas (e quase sempre rotineiras) vozes ainda que certo progresso já esteja sendo observado.

\footnotetext{
Repórteres ainda preferem circular nos gabinetes atapetados das "fontes" credenciadas que em bairros, favelas, hospitais e escolas degradados. Apesar dos progressos recentes, portanto, as matérias ficam devendo uma abordagem mais consistente dos fatos. Políticas sociais prioritárias continuam sendo consideradas sem conteúdo jornalístico, fora de moda, desinteressantes (Motta, 2008: 334).
}

Nas eleições, esse distanciamento pode se acentuar ainda mais, já que, como Krieger (2008) aponta, os jornalistas têm certa tendência a ver intenção política nas ações governamentais, como forma de atrair votos em processos eleitorais futuros. Nos dias em que a disputa por eleitores se acentua, a imprensa parece ter ainda mais receio em se deixar levar pelo discurso dos candidatos (ou seja, não quer ser pautada por eles) e, pode, como decorrência dessa preocupação, buscar sempre a denúncia, a revelação da irregularidade, em vez de dar espaço ao debate entre os políticos sobre temas relevantes, com receio de que isso possa servir apenas de "palanque". Outro motivo associado a esse, que Krieger aponta retomando ideia do jornalista Solano Nascimento, é o de que a cobertura usual dos temas sociais migra de suas editoriais específicas para as equipes que cobrem eleições. Com essa mudança, perde-se o repertório dos possíveis especialistas da área e, consequentemente, cai (ainda mais) a qualidade da cobertura.

Para o estudo, é preciso, então, definirmos primeiramente o que é uma política pública. Canela (2002) a caracteriza como "qualquer ação dos poderes públicos que seja executada a fim de garantir os mais diferentes direitos de cidadãos e cidadãs, segundo o estabelecido no ordenamento jurídico do país" (p. 19). Quanto ao qualificador, social, pode-se entendê-lo como "as ações e os programas voltados para a solução ou melhora das 
condições de vida da população ou para a promoção ou defesa de direitos" (Porto, 2008: $185)$.

Como exemplos de políticas públicas sociais, podemos listar medidas em defesa dos direitos das crianças, das mulheres, dos negros e dos índios; ações no combate à fome e à miséria; estratégias em busca de condições mais igualitárias no acesso à educação e à saúde pública; e planos para a redução dos índices de violência, exploração e abuso sexual. Vários desses temas também podem ser abrigados pelo guarda-chuva do conceito de "desenvolvimento humano", como forma de ampliar a análise do bem-estar social: saindo da ótica exclusiva dos fatores de renda e crescimento econômico e deslocando-se para o olhar do protagonismo do cidadão, ou seja, ações que ampliem as "oportunidades dos indivíduos" (Toledo, 2008: 202). Ressalta-se aqui que, para além da definição de Canela, que foca o papel agenciador dessas políticas nos agentes públicos, há inúmeros atores da sociedade civil que não apenas lutam pela implantação das ações do Estado mas também realizam projetos próprios - seja antes da atuação dos governos ou concomitantemente a ela (cobrindo vácuos e ineficiências deixados pelos governantes).

Neste artigo, analisaremos edições relativas à cobertura eleitoral de dois jornais, a "Folha de S. Paulo", segundo colocado na circulação no país, com cerca de 297 mil exemplares/dia, segundo dados de 2011 (o primeiro é um jornal popular, o "Super Notícia”, de Minas Gerais, sem abrangência nacional) do IVC (Instituto Verificador de Circulação), e o "Correio Braziliense", o veículo impresso mais antigo (e mais consolidado) do Distrito Federal, unidade da Federação que abriga a sede do governo federal, centro gerador de ações de abrangência nacional. O objetivo primeiro é investigar se os dois periódicos cobriram a agenda social, e suas políticas públicas, seguindo o enfoque proposto pelo conceito de "desenvolvimento humano", durante o debate eleitoral de 2010.

Aqui cabe ainda a observação de que tentaremos não nos limitar a olhar apenas o que os jornais poderiam ter feito melhor, mas também o que de fato "cobriram" bem, segundo as orientações de Silva e Paulino (2008). Os autores mostram que a crítica de mídia lança mão do "olhar jornalístico" e, em seu trabalho, também parece ter muito em conta o valor-notícia da irregularidade, do desvio do "devir ser": o que funciona dentro do ordenamento esperado não chama tanto a atenção em relação àquilo que está fora de lugar, como aponta Traquina (2005b). 
Quem sabe, um dia, ainda possamos inferir que existe certa crítica da razão prática jornalística, baseada na observação de experiências exemplares. Haverá, então, uma pedagogia afirmativa do acerto, e não apenas o que existe, hoje, uma pedagogia negativa, focada majoritariamente na existência do erro (Silva \& Paulino, 2008: 134).

\section{Metodologia}

A análise concentrou-se nos cadernos eleitorais dos dois jornais analisados. No caso da "Folha de S. Paulo", quando essas seções especiais não foram publicadas, optamos por estudar o caderno principal de política (Poder), para o qual a cobertura eleitoral (tanto a nacional, em maior número, quanto a regional) migrava. No caso do "Correio", foram analisados os cadernos de Política e Brasil durante todo o período, já que não foram realizados cadernos especiais sobre o período eleitoral (apenas o logo "Eleições 2010" caracterizava o conteúdo que tratava do pleito). As matérias sobre as eleições em Brasília ficaram em outra editoria, voltada para o DF, mas, para que pudesse haver parâmetros de comparação entre os dois veículos e também para que o número de páginas analisadas no "Correio" não apresentasse grande discrepância em relação ao da "Folha", escolheu-se apenas a cobertura mais geral (ainda que temas regionais também tenham aparecido nesse espaço).

Em virtude dos limites de tempo para a pesquisa, optamos por fixar uma seleção de edições (já que não seria possível estudar todos os jornais), tendo como base a eleição do segundo turno, que ocorreu em 31 de outubro. Assim, formulamos uma semana composta (o domingo de uma semana, o sábado da anterior, e assim por diante) para criar uma amostra ao mesmo tempo aleatória e estendida ao longo do tempo, a partir do dia 31 de outubro. Nas tabelas abaixo, seguem as datas e os cadernos: 


\begin{tabular}{|ll|}
\hline \multicolumn{2}{|l|}{ FOLHA } \\
S.PAULO & \\
\hline DATAS & CADERNOS \\
\hline Outubro & \\
\hline Dom, 31 & Eleições 2010 \\
\hline Sáb, 23 & Poder, 1 e 2 \\
\hline Sex, 15 & Poder \\
\hline Quin, 7 & Poder \\
\hline Setembro & \\
\hline Qua, 29 & Eleições 2010 \\
\hline Ter, 21 & Eleições 2010 \\
\hline Seg, 13 & Eleições 2010 \\
\hline Dom, 5 & Eleições 2010 \\
\hline Agosto & \\
\hline Sáb, 28 & \\
\hline Sex, 20 & Poder \\
\hline Quin, 12 & Poder \\
\hline Qua, 4 & Poder \\
\hline Julho & Poder \\
\hline Ter, 27 & \\
\hline Seg, 19 & Poder \\
\hline & Poder \\
\hline
\end{tabular}




\begin{tabular}{|l|l|}
\hline CORREIO & \\
BRAZILIENSE & \\
\hline DATAS & CADERNOS \\
\hline Outubro & \\
\hline Dom, 31 & Política e Brasil \\
\hline Sáb, 23 & Política e Brasil \\
\hline Sex, 15 & Política e Brasil \\
\hline Quin, 7 & Política e Brasil \\
\hline Setembro & \\
\hline Qua, 29 & Política e Brasil \\
\hline Ter, 21 & Política e Brasil \\
\hline Seg, 13 & Política e Brasil \\
\hline Dom, 5 & Política e Brasil \\
\hline Agosto & \\
\hline Sáb, 28 & Política e Brasil \\
\hline Sex, 20 & Política e Brasil \\
\hline Quin, 12 & Política e Brasil \\
\hline Qua, 4 & Política e Brasil \\
\hline Julho & \\
\hline Ter, 27 & Política e Brasil \\
\hline Seg, 19 & Política e Brasil \\
\hline & \\
\hline
\end{tabular}

Após a definição da amostra, optamos por lançar mão da metodologia da análise de conteúdo, quantificando dados e categorizandoos, seguindo os preceitos de Bardin (2002):

O que é a análise de conteúdo atualmente? Um conjunto de instrumentos metodológicos, cada vez mais sutis em constante aperfeiçoamento, que se aplicam a "discursos" extremamente diversificados. O factor comum destas técnicas múltiplas e multiplicadas — desde o cálculo de frequiências que fornece dados cifrados, até à extração de estruturas traduzíveis em modelos - é uma hermenêutica controlada, baseada na dedução: a inferência (p. 11).

Assim, buscamos: identificar as matérias que falavam de políticas públicas sociais (pela ótica do desenvolvimento humano); traçar relações entre elas o número total de textos publicados nos cadernos analisados; e criar categorias, de acordo com o aparecimento dessas ações nas matérias (como citação; tema desenvolvido no texto, mas de modo secundário; foco da matéria). Feita essa identificação, analisar mais profundamente as matérias cuja abordagem da política pública foi maior (a última categoria citada acima). Esse estudo, contudo, também tem de ser feito a partir de certos critérios, para a definição dos quais recorremos à ideia de enquadramento.

Para Porto, enquadramentos "envolvem a seleção de certos aspectos da realidade para fazê-los mais salientes no conteúdo da comunicação e promover uma interpretação causal particular" (1998: 24). São pontos de vista, "atalhos", para que possamos entender a realidade, dando sentido aos fatos (ainda que tenhamos pouca informação sobre o dado analisado). Eles são necessários, segundo o autor, para que possamos enfrentar a complexidade do cotidiano mais facilmente, posicionando-nos frente aos temas, resolvendo problemas, tomando decisões. Todos nós (incluindo os jornalistas, é claro) utilizamos esses atalhos, tecendo relações com nossos valores, com nosso conhecimentos anteriores, ou mesmo com estereótipos cristalizados em nossas mentes. As empresas de comunicação também têm os seus, materializados como políticas editoriais ou ainda como padrões para as rotinas de produção. 
Um texto jornalístico apresenta a realidade de acordo com determinado enquadramento (resumido sobretudo no lead, para a construção do qual o jornalista se vale de valores-notícia, além das técnicas jornalísticas), que é fruto não apenas da opiniões de seus produtores (ainda que o método do jornalista busque a imparcialidade, seus modos de ver sempre estarão presentes no texto; Kovach; Rosenstiel, 2002) e das instituições empresariais que o publica, mas também da coleta de vários outros enquadramentos, traduzidos pelas fontes ouvidas: "Na imprensa, a pluralidade de fontes é um pré-requisito para a inclusão do contraditório nas notícias, enquanto a presença de um número múltiplo de atores sociais contribui para a representação equitativa de todos os interesses" (Motta; Alencar, 2007: 109). Nesse contexto, os meios de comunicação devem, sobretudo, ir além das vozes dos escritórios entapetados, lembrados por Motta, de modo a

ultrapassar a forte dependência em fontes oficiais do Estado e em grupos privilegiados já identificada por diversos autores (Sigal, 1973; Hallin, 1994) e abrir a possibilidade de que a sociedade civil, grupos subalternos e minorias apresentem seus pontos de vista ou enquadramentos (Porto, 1998: 24).

Os enquadramentos dos textos jornalísticos (e os que estão presente neles) não ditam o que os leitores pensarão sobre determinado assunto, mas sem dúvida é importante ferramenta no modo como esse pensamento é formado (e até mesmo para estímular que esse pensar ocorra, segundo a hipótese do agendamento). Desse modo, quanto mais enquadramentos pudermos conhecer, menos superficiais e estereotipados tendem a ser os nossos próprios "atalhos".

Assim, ao analisarmos os textos de "Folha" e "Correio", tentaremos enxergar se e como a política pública social é apresentada (o que se fala dela, por que se fala dela) e as fontes que os jornalistas ouviram para que o debate sobre essa ação fosse tecido (cada um deles com seus respectivos enquadramentos), entendendo, pela teoria do enquadramento, que são bem-vindas a profundidade na discussão e a multiplicidade dos pontos de vista.

\section{Análises}

De todo o período estudado, foram contabilizadas 286 matérias na "Folha" e 276 no "Correio", nos cadernos selecionados. Para esse cálculo, consideramos como "matérias', além das reportagens, apenas as notas com conteúdo um pouco estendido (daí o critério de selecionar as que tinham título). Assim, não foram contados nessa categoria 
artes/infográficos; pequenas notas, sem título; colunas e artigos (apesar de ter havido certa preocupação com estes últimos, como forma de contrapor a pauta do jornal com a de seus articulistas).

\begin{tabular}{|l|l|l|}
\hline \multicolumn{3}{|l|}{ FOLHA DE S.PAULO } \\
\hline DATA & $\begin{array}{l}\text { MATÉRI } \\
\text { AS }\end{array}$ & $\begin{array}{l}\text { ARTIGO E } \\
\text { COLUNA }\end{array}$ \\
\hline Outubro & & \\
\hline Dom, 31 & 27 & 2 \\
\hline Sáb, 23 & 23 & 2 \\
\hline Sex, 15 & 25 & 4 \\
\hline Quin, 7 & 29 & 4 \\
\hline Setembro & & \\
\hline Qua, 29 & 35 & 4 \\
\hline Ter, 21 & 19 & 4 \\
\hline Seg, 13 & 22 & 3 \\
\hline Dom, 5 & 20 & 5 \\
\hline Agosto & & \\
\hline Sáb, 28 & 16 & 2 \\
\hline Sex, 20 & 20 & 3 \\
\hline Quin, 12 & 12 & 3 \\
\hline Qua, 4 & 11 & 4 \\
\hline Julho & & \\
\hline Ter, 27 & 18 & 2 \\
\hline Seg, 19 & 9 & 2 \\
\hline Total & $\mathbf{2 8 6}$ & $\mathbf{4 4}$ \\
\hline & & \\
\hline
\end{tabular}




\begin{tabular}{|l|l|l|}
\hline \multicolumn{3}{|l|}{ CORREIO BRAZILIENSE } \\
\hline DATA & MATÉRIAS & $\begin{array}{l}\text { ARTIGO E } \\
\text { COLUNA }\end{array}$ \\
\hline Outubro & & \\
\hline Dom, 31 & 29 & 3 \\
\hline Sáb, 23 & 18 & 2 \\
\hline Sex, 15 & 23 & 2 \\
\hline Quin, 7 & 15 & 2 \\
\hline Setembro & & \\
\hline Qua, 29 & 22 & 3 \\
\hline Ter, 21 & 16 & 2 \\
\hline Seg, 13 & 13 & 1 \\
\hline Dom, 5 & 14 & 3 \\
\hline Agosto & & \\
\hline Sáb, 28 & 27 & 2 \\
\hline Sex, 20 & 22 & 2 \\
\hline Quin, 12 & 23 & 2 \\
\hline Qua, 4 & 16 & 3 \\
\hline Julho & & \\
\hline Ter, 27 & 23 & 2 \\
\hline Seg, 19 & 15 & 1 \\
\hline Total & $\mathbf{2 7 6}$ & $\mathbf{3 0}$ \\
\hline & & \\
\hline
\end{tabular}

No primeiro caso, a "Folha", 29 matérias (e mais 8 artigos e colunas) abordaram políticas públicas sociais de algum modo (tabela 5), ainda que em 14 delas tenha havido apenas citação (11 desenvolveram o tema, mas com poucas linhas de contextos ou explicativas, e apenas 4 tiveram o assunto como tema mais central, ligado ao aspecto eleitoral). No "Correio", foram 27 textos (e mais 3 artigos ou colunas), dos quais 18 apenas citavam as políticas públicas sociais e outras 8 desenvolveram mais a abordagem do tema. $\mathrm{O}$ assunto foi foco apenas de 1 matéria. Traduzindo esses números, temos que cerca de $10 \%$ dos textos da Folha tocaram em políticas públicas sociais, mas apenas $1 \%$ tiveram o assunto como centralidade. Se somarmos a estas últimas as matérias que desenvolveram um pouco mais o tema, teremos $5 \%$. No "Correio", os números são, respectivamente: $10 \%$; 0,3\%; e $3,3 \%$. Veja abaixo: 


\section{Gráfico 1}

\section{Folha: políticas públicas nas matérias}

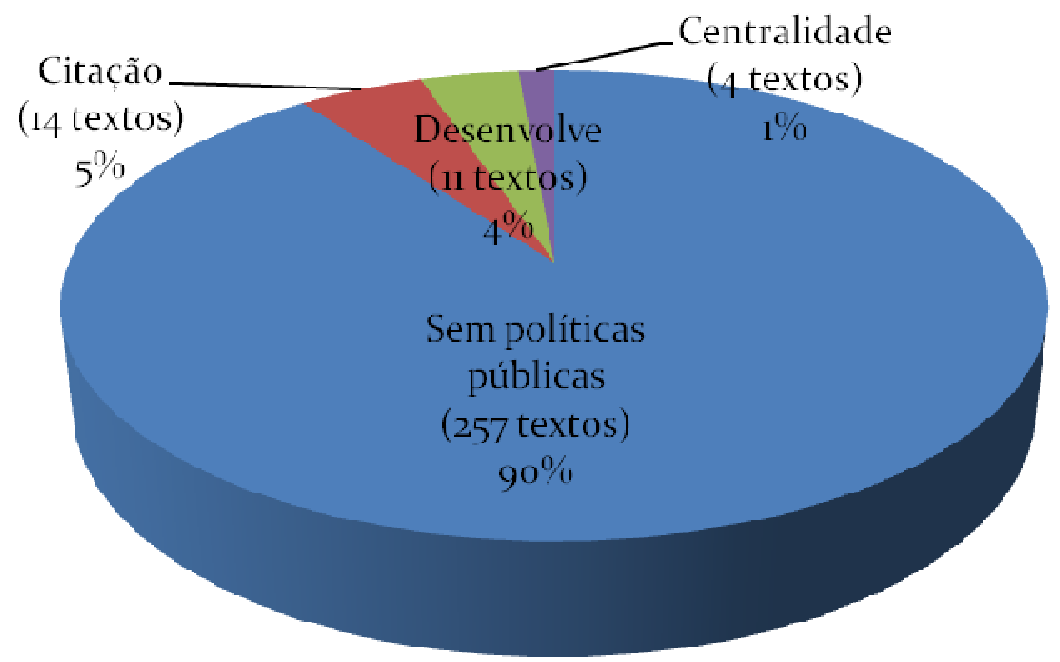

\section{Gráfico 2}

Correio Braziliense: políticas públicas nas matérias

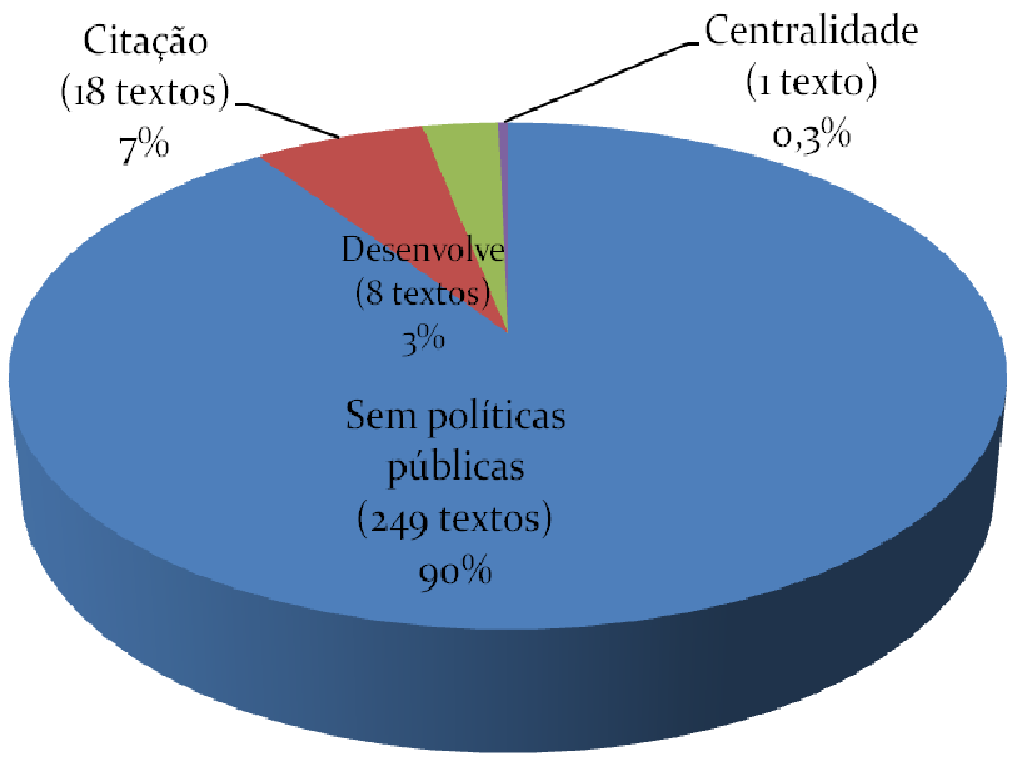

Reuista Anagrama: Reuista Científica Interdisciplinar da Graduação

Ano 5 - Edição 4 Junho-Setembro 2012

Auenida Professor Lúcio martins Rodrigues, ЧЧ३, Cidade Uniuersitária, São Paulo, CEP: 05508-900 anagrama ausp.br 
Esses dados mostram que a cobertura de políticas públicas sociais nesses dois jornais, no período eleitoral de 2010, foi pequena, apesar da importância do tema para o debate de ideias e propostas que se supõe haver no pleito, conforme já lembrou Canela (2008). A análise dos títulos dos textos em que as políticas sociais apareceram mostra que elas surgiram, em geral, da cobertura da agenda dos candidatos, de debates (em momentos em que os temas foram comentados pelos políticos ou apareceram nas questões) e de pesquisas (citando opiniões e críticas dos candidatos, muitas vezes relacionado-as ao seu desenvolvimento nas previsões de votos, como "Risco de $2^{\circ}$ turno leva Dilma a acionar Lula", "Ao ataque no segundo round" e "Para eleitor, Dilma é a continuidade, e Serra, o experiente", na "Folha"; e "Lula toma as rédeas para evitar naufrágio" e "Bolsões de pobreza e de votos", no "Correio").

Esse dado, por outro lado, pode demonstrar que as políticas públicas ao menos estiveram presentes no discurso dos candidatos no jogo político de 2010, ainda que não tenha havido a devida contextualização por parte da imprensa. Um dos motivos para o não aprofundamento pode ser o fato de os repórteres fugirem dos discursos propositivos dos candidatos porque veem aí uma forma de servir de palanque para os políticos (deixando-se ser pautados por eles), conforme apontado por Krieger (2008). Em nossa "leitura flutuante" (Bardin, 2002) do período, nota-se que as denúncias de corrupção e de desvios de recursos ganharam grande peso na cobertura, na tentativa de encontrar "buracos" nos discursos dos candidatos. A imprensa perdeu a oportunidade, no entanto, de contrapor as propostas de plano de governo (quando existiam) à realidade do país e a condições de viabilidade. A "Folha" teve um exemplo disso na matéria "Ao ataque no segundo round", de 31 de outubro, criticando as condições de cumprimento de algumas ideias dos candidatos (classificando três propostas de Dilma e três de Serra com os rótulos de "há limitações" e “difícil de cumprir"), mas, infelizmente, isso ficou restrito a uma arte, no pé de página, com frases curtas e sem vozes de especialistas. O mesmo aconteceu no "Correio", com a matéria "Duro de acreditar", na qual as propostas dos três principais candidatos também foram avaliadas apenas pelo jornal — sem especialistas para comprovar ou refutar essa análise.

Nesse contexto, houve destaque para o tema do aborto, que foi abordado pela temática moral e religiosa, e não como política pública: fato notado pelo número de textos em que o tema foi apenas mencionado: 7 das 14 citações da "Folha" (entre as matérias que desenvolvem um pouco mais o tema, são 2 de 11 ; nenhum texto teve o assunto como 
foco); no "Correio", 7 das 18 citações (2 dos 8 textos que desenvolveram mais o tema; e nenhuma matéria teve o aborto como assunto principal). Como exemplos disso, temos os textos "Plano de Dilma foca ambiente e religião"; "Lula cita Deus e se diz vítima de mentiras" e "Partido é oportunista sobre o aborto, diz bispo", na "Folha"; e "Guerra santa aberta" e "Religião no discurso e no telemarketing", no "Correio". Veja todos os dados nos gráficos 3 e 4, que trazem o aborto como uma categoria à parte de saúde, para ressaltar o fato observado, e ainda mostram a frequência alta também de Bolsa Família, um dos programas mais populares do governo Lula, ainda que nunca tenha aparecido como foco do texto: o benefício apareceu em 6 das 29 matérias que exploraram políticas públicas sociais na "Folha" (20\%) e em 9 das 27 no "Correio" (33\%) - como citação ou com pouco mais de desenvolvimento.

Tabela 5

FOLHA - IDENTIFICAÇÃO DE POLÍTICAS PÚBLICAS SOCIAIS

\begin{tabular}{|c|c|c|}
\hline Data & Matéria & Aparição \\
\hline 31/out & $\begin{array}{l}\text { Dilma tem } 55 \% \text { dos votos válidos, e } \\
\text { Serra, } 45 \%\end{array}$ & Citação (descriminalização do aborto) \\
\hline 31/out & $\begin{array}{l}\text { Para eleitor, Dilma é a } \\
\text { continuidade, e Serra, o experiente }\end{array}$ & Citação (Bolsa-Família) \\
\hline 31/out & Com Lula em turno integral & $\begin{array}{l}\text { Desenvolve, mas não é o foco (creche e salário } \\
\text { mínimo) }\end{array}$ \\
\hline 31/out & Ao ataque no segundo round & $\begin{array}{l}\text { Desenvolve, mas não é o foco (salário mínimo e } \\
\text { Bolsa Família) }\end{array}$ \\
\hline 31/out & 20 perguntas para Dilma e Serra & $\begin{array}{l}\text { Políticas públicas é o foco, incluindo as sociais } \\
\text { (saúde, educação, Bolsa Família e segurança) }\end{array}$ \\
\hline 15/out & $\begin{array}{l}\text { Novo programa de governo de } \\
\text { Dilma traz críticas a Serra }\end{array}$ & $\begin{array}{l}\text { Citação (aborto, trabalho, habitação, segurança, } \\
\text { saúde, erradicação da pobreza, educação) }\end{array}$ \\
\hline 15/out & $\begin{array}{l}\text { Para especialistas, agenda negativa } \\
\text { é natural no segundo turno }\end{array}$ & $\begin{array}{l}\text { Citação (Bolsa Família, "universidade, carne na } \\
\text { mesa e luz" são "direitos de todos") }\end{array}$ \\
\hline 15/out & $\begin{array}{l}\text { Lula cita Deus e se diz vítima de } \\
\text { mentiras }\end{array}$ & Citação (aborto) \\
\hline 15/out & $\begin{array}{l}\text { José Serra diz ser a favor da união } \\
\text { civil entre homossexuais }\end{array}$ & Foco da matéria (casamento homossexual) \\
\hline 15/out & $\begin{array}{l}\text { Weslian diz desconhecer seu } \\
\text { programa de governo }\end{array}$ & Citação (aborto) \\
\hline 07/out & $\begin{array}{l}\text { Plano de Dilma foca ambiente e } \\
\text { religião }\end{array}$ & Citação (aborto) \\
\hline
\end{tabular}




\begin{tabular}{|c|c|c|}
\hline 07/out & $\begin{array}{l}\text { Luz para todos não cumpre metas e } \\
\text { é prorrogado de novo (com artigo) }\end{array}$ & Foco da matéria (Luz para Todos) \\
\hline 07/out & $\begin{array}{l}\text { Dilma debate homofobia com } \\
\text { evangélico }\end{array}$ & Desenvolve, mas não é o foco \\
\hline 07/out & $\begin{array}{l}\text { Partido é oportunista sobre } 0 \\
\text { aborto, diz bispo }\end{array}$ & Desenvolve, mas não é o foco \\
\hline 07/out & $\begin{array}{l}\text { PT não levará polêmica ao horário } \\
\text { eleitoral }\end{array}$ & Desenvolve, mas não é o foco (aborto) \\
\hline 29/set & $\begin{array}{l}\text { Risco de } 2^{\circ} \text { turno leva Dilma a } \\
\text { acionar Lula }\end{array}$ & Citação (aborto e casamento homossexual) \\
\hline 29/set & $\begin{array}{l}\text { Com Alckmin, reprovação aumenta } \\
\text { e matrículas caem }\end{array}$ & Foco da matéria \\
\hline 29/set & $\begin{array}{l}\text { Alvo, Alckmin se esquiva de } \\
\text { confrontos }\end{array}$ & Citação (Vila Dignidade) \\
\hline 29/set & $\begin{array}{l}\text { No primeiro debate, mulher de } \\
\text { Roriz não responde perguntas }\end{array}$ & Citação (aborto) \\
\hline $21 /$ set & $\begin{array}{l}\text { Em debate, Tucano defende } 13^{\circ} \\
\text { para Bolsa Família }\end{array}$ & Desenvolve, mas não é o foco \\
\hline $13 /$ set & $\begin{array}{l}\text { Candidatos } \\
\text { propostas }\end{array}$ & Desenvolve, mas não é o foco (educação, saúde) \\
\hline 05/set & $\begin{array}{l}\text { Dilma ignorou falha apontada por } \\
\text { TCU em contas de luz; prejuízo é } \\
\text { de } \mathrm{R} \$ 1 \text { bi* }\end{array}$ & $\begin{array}{l}\text { Desenvolve, mas não é o foco (tarifa social de } \\
\text { energia) }\end{array}$ \\
\hline 05/set & $\begin{array}{l}\text { Emprego e nativismo sustentam } \\
\text { idolatria a Lula em Pernambuco }\end{array}$ & Desenvolve, mas não é o foco (Bolsa Família) \\
\hline 05/set & $\begin{array}{l}\text { Candidatos ao governo são } \\
\text { acusados de usar máquina (MG)* }\end{array}$ & Citação (Telecentros) \\
\hline 12/ago & $\begin{array}{l}\text { Fazenda erra dados e infla feitos de } \\
\text { Lula }\end{array}$ & Desenvolve, mas não é o foco (salário mínimo) \\
\hline 12/ago & $\begin{array}{l}\text { Dilma afirma que não pode ocultar } \\
\text { dados sobre o país }\end{array}$ & Citação (Bolsa Família) \\
\hline 04/ago & $\begin{array}{l}\text { Por TV, Dilma improvisa agenda } \\
\text { positiva }\end{array}$ & Citação (ProUni) \\
\hline 27/jul & $\begin{array}{l}\text { PT questiona "legado" de Serra na } \\
\text { Saúde }\end{array}$ & $\begin{array}{l}\text { Desenvolve, mas não é o foco (genéricos, Aids } \\
\text { e SUS) }\end{array}$ \\
\hline 19/jul & $\begin{array}{l}\text { Presidenciáveis recorrem } \\
\text { repeteco }\end{array}$ & $\begin{array}{l}\text { Citação (Fundo de Amparo ao Trabalhador e } \\
\text { Seguro Desemprego) }\end{array}$ \\
\hline & $\begin{array}{l}\text { *Matéria com "Outro lado" } \\
\text { também cita a política pública }\end{array}$ & \\
\hline ARTIG & S E COLUNAS & \\
\hline 31/out & $\begin{array}{l}\text { Acirramento e placar abaixo de } \\
60 \% \text { fazem } 2010 \text { remeter a } 1989 \\
\text { (Mauro Paulino e Alessandro } \\
\text { Janoni (DataFolha)) }\end{array}$ & Citação (aborto) \\
\hline 07/out & Aborto em campanha (Toda Mídia) & Citação (aborto) \\
\hline 07/out & $\begin{array}{l}\text { Potencial fez do programa alvo de } \\
\text { loteamento de cargos (Eduardo } \\
\text { Scolese) }\end{array}$ & Foco (Luz para Todos) \\
\hline 03/set & $\begin{array}{l}\text { Está na cara: Alckmin } \mathrm{e} \\
\text { Mercadante (David Matsumoto) }\end{array}$ & $\begin{array}{l}\text { Citação (fundo de moradia para "pessoas } \\
\text { carentes") }\end{array}$ \\
\hline 04/ago & $\begin{array}{l}\text { O debate dos fracassos enriquece a } \\
\text { agenda (Elio Gaspari) }\end{array}$ & $\begin{array}{l}\text { Desenvolve bastante, mas não é o foco (Bolsa } \\
\text { Família; Fome Zero; Cartão SUS) }\end{array}$ \\
\hline 27/jul & $\begin{array}{l}\text { Vitória de Serra ou de Dilma não } \\
\text { significa redução da violência no } \\
\text { campo (Eduardo Scolese) }\end{array}$ & Desenvolve, mas não é o foco \\
\hline
\end{tabular}




\begin{tabular}{|lll|}
\hline $\mathbf{2 7} / \mathbf{j u l}$ & Tiroteio (Poder) & Citação (computador por aluno) \\
\hline $\mathbf{1 9 / j u l}$ & Ao mundo (Toda Mídia) & Citação (Bolsa Família) \\
\hline
\end{tabular}

\section{Tabela 6}

\section{CORREIO - IDENTIFICAÇÃO DE POLÍTICAS PÚBLICAS SOCIAIS}

\begin{tabular}{|c|c|c|}
\hline Data & Matéria & Aparição \\
\hline 31/out & O futuro do país & Desenvolve, mas não é o foco (genérico) \\
\hline 31/out & Programa, ainda que tardio & Desenvolve, mas não é o foco (Bolsa Família) \\
\hline 31/out & Detalhes, só quando governar & Citação (Bolsa Família) \\
\hline 31/out & $\begin{array}{l}\text { Gratidão do técnico de } \\
\text { desempregado }\end{array}$ & Citação (Prouni) \\
\hline 23/out & $\begin{array}{l}\text { Dilma adula prefeitos de Minas } \\
\text { Gerais }\end{array}$ & Citação (Bolsa Família; Minha Casa, Minha Vida) \\
\hline 23/out & Temporada de agrados & Citação (programas sociais estaduais) \\
\hline 23/out & Partidos descartam baixar a guarda & Citação (aborto) \\
\hline 23/out & Apoio polêmico e dispensável & Citação (aborto) \\
\hline 15/out & $\begin{array}{l}\text { Lula toma as rédeas para evitar } \\
\text { naufrágio }\end{array}$ & Citação (Bolsa Família e aborto) \\
\hline 15/out & Mudanças trabalhosas & Citação (Minha Casa, Minha Vida) \\
\hline 15/out & Farpas afiadas na TV & Citação (aborto) \\
\hline 15/out & Cereja do bolo & Citação (aborto) \\
\hline 15/out & $\begin{array}{llll}\text { Religião no discurso e no } \\
\text { telemarketing }\end{array}$ & Desenvolve, mas não é o foco (aborto) \\
\hline 15/out & "Contrarreforma" pró Dilma & Citação (aborto) \\
\hline 7/out & Bolsões de pobreza e de votos & Desenvolve, mas não é o foco (Bolsa Família) \\
\hline 7/out & Guerra santa aberta & Desenvolve, mas não é o foco (aborto) \\
\hline 29/set & $\begin{array}{l}\text { Discurso otimista, mas tempo } \\
\text { restrito }\end{array}$ & Citação (Bolsa Família) \\
\hline 29/set & Renegadas nas urnas e no PT & Citação (Minha Casa, Minha Vida) \\
\hline $5 /$ set & E da luz se fez a morte & Citação (SUS) \\
\hline $5 /$ set & $\begin{array}{l}\text { Os sonhos interrompidos no } \\
\text { hospital }\end{array}$ & Citação (Saúde da Família) \\
\hline $5 /$ set & O início de uma dor sem fim & Citação (SUS) \\
\hline 28/ago & $\mathrm{Na}$ garupa de Lula & $\begin{array}{l}\text { Desenvolve, mas não é o foco (Bolsa Família; } \\
\text { Minha Casa, Minha Vida) }\end{array}$ \\
\hline $28 / 08$ & Campanha em duas frentes & Citação (aborto) \\
\hline 20/ago & $\begin{array}{l}\text { Minha Casa, Minha Vida é } \\
\text { investigado }\end{array}$ & Foco da matéria (Minha Casa, Minha Vida) \\
\hline 27/jul & $\begin{array}{l}\text { Marina critica Bolsa Família } \\
\text { eternizada }\end{array}$ & Desenvolve, mas não é o foco (Bolsa Família) \\
\hline 27/jul & Duro de acreditar & Desenvolve, mas não é o foco (Bolsa Família) \\
\hline 19/jul & $\begin{array}{l}\text { No Enem públicas do Rio de } \\
\text { destacam }\end{array}$ & Citação (Prouni) \\
\hline \multicolumn{3}{|c|}{ ARTIGOS E COLUNAS } \\
\hline 31/out & O povo escolhe & Citação (Bolsa Família; Minha Casa, Minha Vida) \\
\hline
\end{tabular}




\begin{tabular}{|lll|}
\hline 15/out & Alguns pontos & Citação (aborto) \\
\hline 15/out & Dilma nas cordas & Citação (aborto) \\
\hline
\end{tabular}

\section{Gráfico 3}

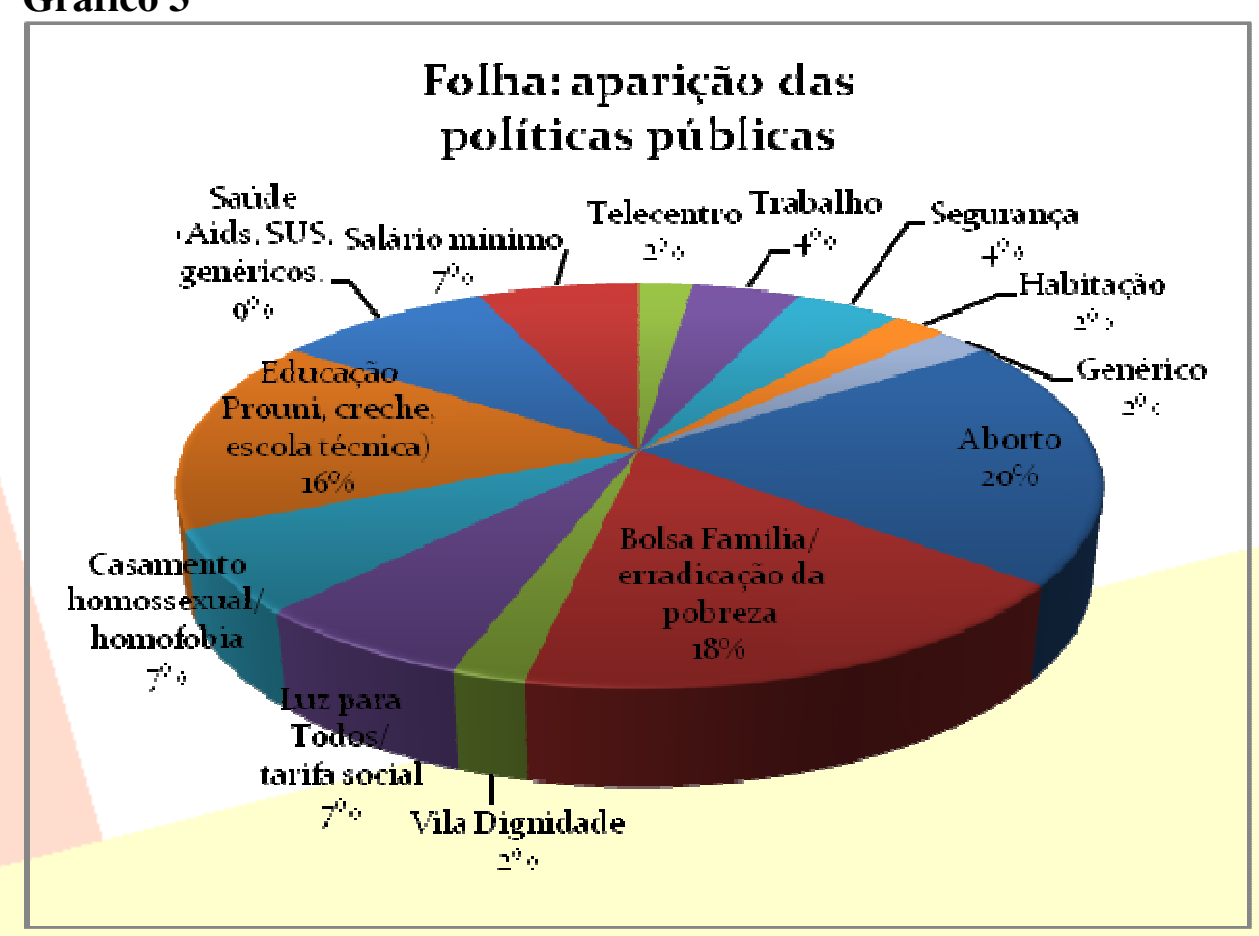

\section{Gráfico 4}

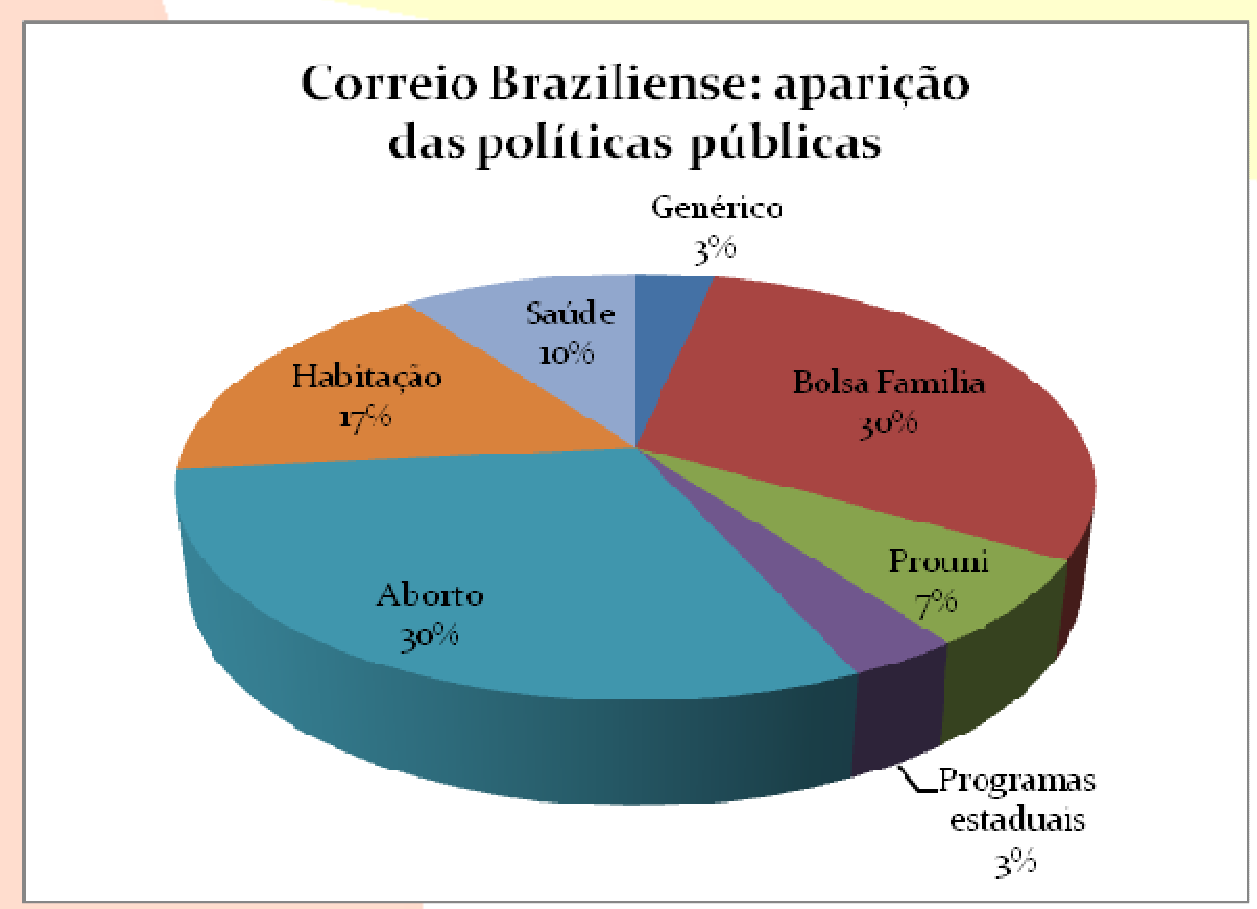

Reuista Anaprama: Reuista Científica Interdisciplinar da Graduação

Ano 5 - Edição 4 Junho-Setembro 2012

Auenida Professor Lúcio martins Rodrigues, ЧЧ३, Cidade Uniuersitária, São Paulo, CEP: 05508-900 
Pelos limites deste artigo, e para analisar com mais profundidade a cobertura, passaremos a avaliar especificamente as matérias em que a política pública foi o foco. $\mathrm{O}$ estudo dos textos em que o assunto foi apenas citado ou que teve um pouco mais de desenvolvimento poderia enviesar a pesquisa, porque contabilizaria fontes $\mathrm{e}$ enquadramentos que não estariam relacionados às políticas sociais, mas sim aos temas centrais das matérias. Foram avaliados seis textos, incluindo uma análise assinada por um editor, que, apesar de ser um texto opinativo, aparece ligada a uma reportagem maior, que também aborda política pública social. No "Correio", infelizmente, apenas um texto teve foco no assunto.

$\mathrm{Na}$ "Folha", nos cinco textos, as políticas sociais que mais apareceram estavam relacionadas à educação e ao programa Luz para Todos (que leva energia elétrica para famílias que vivem no campo). Outras ações que também tiveram espaço foram Bolsa Família e Saúde da Família, além da questão do casamento entre homossexuais. Os temas apareceram porque faziam parte de alguma forma da agenda de campanha dos candidatos, ou porque se tratava de algum tipo de denúncia (do não cumprimento de metas) ou de refutação (de dados levantados pelos candidatos). As fontes oficiais foram as vozes ouvidas - representadas pela figura dos próprios candidatos (ou de suas assessorias) ou por órgão do governo —, as quais listamos aqui: José Serra, Dilma Rousseff, Geraldo Alckmin, Ministério das Minas e Energia e Tribunal de Contas. Em nenhuma das matérias havia a opinião de especialistas ou personagens.

No "Correio", não foi muito diferente. A única matéria que trazia o tema como foco principal ("Minha Casa Minha Vida é investigado") falava de uma denúncia, afirmação que pode ser comprovada pelas fontes utilizadas: Ministério Público e a candidata governista, Dilma Rousseff. Na abordagem do assunto faltaram personagens (talvez uma família que não tenha sido beneficiada pelo programa em decorrência dos desvios); e também poderia ter sido feita uma análise da notícia, ou uma contextualização, de forma mais clara, de como o programa funciona.

$\mathrm{Na}$ amostra utilizada, o jornal citou programas sociais por diversas vezes e também fez referências à saúde e à erradicação da miséria, entre outros temas. No entanto, pecou por não avançar nesses assuntos. Fora da amostra, porém, encontramos, na edição de 8 de julho (dois dias após a disputa eleitoral ser autorizada), uma matéria sobre educação que atendia praticamente todos os itens que procurávamos: pluralidade de fontes, dados estatísticos e personagens. O texto "Uma triste realidade" abria uma série de reportagens 
especiais, que seriam publicadas nas edições de quinta-feira, por três meses, intitulada "Desafios do presidente". Contudo, nas duas semanas seguintes, não foram divulgadas novas reportagens - outra publicação ocorreria apenas no dia 29 de julho e traria a questão ambiental e agrícola para o debate ("Terra devastada pelo descaso"). Mais uma reportagem da série foi divulgada no dia 16 de setembro e tinha como título "Salvação depois do trauma" (sobre exploração sexual infantil). Ou seja, além de ter descumprido com o prometido em relação à frequência das matérias, o jornal apresentou, em três meses, apenas três textos.

\section{Considerações finais}

Assim, podemos perceber, nos exemplos citados ao longo do texto, que os jornais impressos estudados não se comprometeram com uma agenda social ativa. Por mais que algumas matérias abordassem políticas públicas, não houve um compromisso com o eleitor de aprofundar o tema. Mesmo assim, é importante ressaltar que os grandes personagens dessas eleições, os próprios candidatos, parecem ter preferido não debater. Uma escolha feita por eles mesmos. Caso tivessem abraçado o confronto de ideias, os periódicos não teriam como deixar de abordá-lo, ainda que isso ocorresse de maneira não satisfatória.

Esses dados nos permitem afirmar que os jornais não apenas deixaram de cobrir políticas públicas, mas as cobriram mal: faltaram enquadramentos diversificados (além dos do repórter, do jornal e do candidato), que poderiam trazer outros entendimentos e que, portanto, ofereceriam visões mais complexas e diversificadas dos fatos noticiados. Mesmo a fonte oficial que não era de campanha careceu de voz própria: o Ministério das Minas e Energia virou "entrevistado", e não um técnico ou um diretor da área em questão; o Tribunal de Contas foi ouvido por um relatório; o Ministério Público Federal tornou-se um autor de denúncia, mas seria tão difícil ouvir um procurador? Sabe-se que a falta de estrutura e de pessoal nas redações é um entrave significativo para a feitura do bom jornalismo, mas até que ponto a rotina contra o relógio impede uma conversa por telefone, que possa contextualizar os dados de uma folha de papel? Por que a leitura do jornalista tem de ser a única? Faltaram novos olhares e o confronto de diferentes ideias.

Além disso, os jornais deixaram de suscitar questões que pudessem preocupar o eleitor, como as filas dos hospitais, a falta de segurança e de saneamento e a deficiência do sistema educacional, entre tantas outras, e preferiram, sobretudo, dar espaço para o tão 
comentado e "suitado" tema do aborto. Se essas questões foram deixadas de lado pelos candidatos, os jornais poderiam ter se utilizado de seu poder de agendar temas para inserilas no debate. No entanto, isso também não foi observado.

Desse modo, podemos dizer que é evidente que os temas sociais perderam potência em um período tão propício para o questionamento. O processo eleitoral não se resume ao ato de votar: é necessária a busca de informações, interpretações e pesquisas. E a mídia poderia ter sido um agente importante no fomento dessas reflexões. Ainda que a cobertura de políticas públicas não fosse vasta, a qualidade dos textos que delas tratassem poderia sanar o vácuo do assunto nas pautas diárias. Mas parece que o tema está fora da ordem eleitoral do "Correio" e da "Folha".

\section{Referências}

BARDIN, Laurence. Análise de conteúdo. Lisboa: Edições 70, 2002.

CANELA, Guilherme. "A cobertura jornalística das políticas públicas: elementos para debate”. In: CANELA, Guilherme (Org.). Políticas públicas sociais e os desafios para o jornalismo. São Paulo: Cortez; Andi, 2008.

KOVACH, Bill; ROSENSTIEL, Tom. Os elementos do jornalismo: o que os jornalistas devem saber e o público exigir. São Paulo: Geração Editorial, 2003.

KRIEGER, Gustavo. "As políticas sociais no contexto das eleições". In: CANELA, Guilherme. (Org.). Políticas públicas sociais e os desafios para o jornalismo. São Paulo: Cortez; Andi, 2008.

MOTTA, Luiz G.; ALENCAR, Railssa P. "Eleições de 2006: pluralismo e representação social na mídia brasileira". Logos. Rio de Janeiro: Uerj, n. 27, $2^{\circ}$ semestre de 2007, p. 108126.

MOTTA, Luiz G. "E agora? Urgente colocar o social no centro da pauta jornalística”. In:

CANELA, Guilherme. (Org.). Políticas públicas sociais e os desafios para o jornalismo.

São Paulo: Cortez; Andi, 2008.

PORTO, Mauro P. “A mídia e a avaliação das políticas públicas sociais”. In: CANELA,

Guilherme. (Org.). Políticas públicas sociais e os desafios para o jornalismo. São Paulo:

Cortez; Andi, 2008.

"Muito além da informação: mídia, cidadania e o dilema democrático". São

Paulo em perspectiva. São Paulo: Fundação Seade, v.1 2, n.4, out.-dez. 1998, p. 17-25. 
SILVA, Luís M. da; PAULINO, Fernando. O. "Por que os observatórios não observam "boas práticas"? In: CHRISTOPHOLETTI, Rogério; MOTTA, Luiz. G. (Orgs.). Observatórios de mídia: olhares da cidadania. São Paulo: Paulus, 2008.

TOLEDO, José R. de. "O ser humano no centro do desenvolvimento". In: CANELA, Guilherme. (Org.). Políticas públicas sociais e os desafios para o jornalismo. São Paulo: Cortez; Andi, 2008.

TRAQUINA, Nelson. Teorias do Jornalismo: v. 1. Florianópolis: Insular, 2005. Teorias do Jornalismo: v. 2. Florianópolis: Insular, 2005b. 